\title{
Improved Auto Majors Innovative Practice Teaching and Research Capabilities
}

\author{
Lin $\mathrm{Hu}$, Fangyi Li, Xin Liu \\ School of Automotive and Mechanical Engineering \\ Changsha University of Science and Technology \\ Changsha, China
}

\author{
Huang Jing \\ College of Mechanical and Vehicle Engineering \\ Hunan University \\ Changsha, China
}

\begin{abstract}
Due to our traditional concepts of education and the rapid development of automotive technology, we need to improve and perfect the innovative practice teaching system for vehicle major students. This paper analyzed and concluded the current situation and existing problem of practice training, and according to the actual characteristics of the automotive specialty teaching, this paper proposed a complete solution to improve the students 'practice ability', which includes setting legitimate curriculum system, building practical ability training platform, optimizing multidimensional practice teaching quality assurance system, and improving the ability assessment methods.
\end{abstract}

Keywords-Automotive specialty, innovative ability, curriculum, practice platform, the quality assurance system

\section{INTRODUCTION}

Auto industry, with concentrated capital, technology and talents coupled with widely employment, has been a important pillar industry of national economy. With the rapid development of automobile industry in our country, there is an increasingly demand for auto majors both in society and the enterprises. So many universities and colleges set up automotive major, such as vehicle engineering, automobile service engineering, etc.[1] to adapts the social requirements. In the traditional training model of automotive majors, the student mainly rely on the campus's practice base to finish the innovative practices training-a very significant training. And the off-campus practice is nearly a cursory visit which is lack of opportunities as well as condition to participate in real production practices and lack of innovation training. Therefore, a serious gap between graduates and the practice of training emerged from this mode, they lack of innovative ability and ability to solve practical engineering problems. However, the spirit of innovation and practical ability is not only the soul of a nation's progress, but also an inexhaustible motive force for the prosperity of a country. So America, Japan, Germany, Switzerland and other countries all attach great importance to the cultivation of innovative practice talent. And they train it by curriculum plan, teaching methods, practical activities, entrepreneurship education, talents training and other aspects. Thus, to our students major in automobile, at the same time not neglecting the theoretical capacity, should strengthen the cultivation of innovation and practical ability.

\section{THE CURRENT SITUATION OF AUTOMOBILE MAJORS INNOVATION AND PRACTICE ABILITY}

\subsection{Automotive majors in our country lack of innovative ability are reflected in these aspects follows}

(1)Lacking sense of innovation and confidence as well as not good at creating and using conditions.

Sense of innovation is not only the power inside of the innovative activities, but also the conscious sense, strong desire and positive emotions when individuals were in innovative activities. The sense of innovation mainly shows in these aspects that if usually able to do innovative activities consciously and if have a high level of proactive innovating ${ }^{[3]}$.On one hand, our students lacking of indispensable innovation elementary education and was influenced by the traditional culture. On the other hand, their teacher, who working on examination-oriented education for a long time, didn't pay enough attention on inspiring and guiding. So graduates have no individuality, confidence, spirit of adventure and without sense of innovation as well as initiative.

(2)Their innovative knowledge is so weak that can't grasp the latest development of their subject.

In our country's colleges and universities, the setup of automotive major has much in common. They use unified textbooks, teaching plan and curriculum, so that the knowledge between subjects repeats seriously. What's more, because of the less connection between curriculum and less setup in adjacent disciplines and interdisciplinary, the student has fewer opportunities to learn the foremost development of the discipline and update their knowledge too slowly. Moreover, the knowledge student got in the close campus is too rigid to them to realize the value of knowledge. Therefore, they keep existing knowledge structure without willing to explore and innovate voluntarily. In the long run, the backward situation of knowledge formed ${ }^{[4]}$.

(3)Poor innovation and weak innovation skills.

Because deficient facilities and the stress of running school has reduced the opportunities for students to put their knowledge into practice, so that the automobile majors is often behind closed doors when they proceed the scientific research, which seriously block students to advance their innovation skills and achieve their innovation.

\subsection{The current situation of automotive class students' practical ability in China is not optimistic}

(1)Experiment, practice, design and other practical teaching is nearly the knowledge verification and duplication in the known field, which is lacking of experimental techniques, experimental design, experimental methods and the cultivation as well as training on independent practical ability, so that students is hard to get innovative practice ability. With the expansion of enrollment, the investment on laboratories equipment and the personnel equipped is lagging behind, 
what cause many laboratory with much person less facility, the student is just listening the laboratory instead of practicing. The practice phase is nearly a cursory visit, the purpose of practice is unclear, the construction of practice base is relatively weak and the utilitarian practice unit made student difficult to get a deeply understanding about the production process and practice. On the one hand, there indeed have some differences between the students when it comes to graduate curriculum design or design. On the other hand, there are many disadvantages existed in the energy input of teacher and stuff, the design phase only get a little success which belongs to a building block type of technology cobble and imitation in most cases with rare innovation.

(2)Have no system planning and design during the practice teaching. For automobile specialty, in the aspects of practice ability training, not like the theory of curriculum with careful analysis and determined a reasonable training plan. The experiment of each courses are self-contained, so that student hard training their ability on explore the unknown and innovation from the practice teaching. And contact between practice teaching is not tight enough, and even there is a disconnect, repeat and other phenomena. Thus, what is the most significant to advance the teaching quality is to planning and optimizing the practice teaching system of Machine speciality scientifically and systematically.

(3)There have no cooperation among the laboratory teaching, producing practice, curriculum design and the Research and Development Center of IAR. By other's faults, wise men correct their own. America has been very successful in terms of innovative education. Since the 1990s, American university keeps moving on education innovation. They adhere the concept: one "center" and three "combination"--take the student as the center, combining the in-class and after-class, combining the science and humanities, combining the teaching and research. Then formed a unique and innovative training model step by step. What's more, they pay a great attention on the cooperation between university and industry. American has more than 1000 various types of cooperative research center between university and industry in 200 universities. And the funds afford by government and industry, the center has provided acooperative research and innovation stage for technological innovation talents from university or industry. From the American experience we can see that the school-enterprise cooperation and the mutual promotion between teaching and research have played a momentous role over the training about innovative ability.

(4)Assessment methods of practical teaching should be improved. Scientific assessment methods can promote student to learn engineering practice and a bad one may hinder their learning motivation. But due to the particularity of the practical teaching, it can't be check by a simple examination. Because the assessment of practical teaching has certain blindness and conformity, the results of the assessment are also can't let the student to do some improvement. For example, the practical teaching is limited by the environment and conditions and lack of a sound system to manage and rule it. Moreover, the phenomenon, students fabricate the experimental data and copy the report, is hard to stop.

III. RESEARCH ON METHOD OF IMPROVING THE AUTOMOBILE MAJORS' INNOVATIVE PRACTICE ABILITY

On the basis of the research about China's present situation and experience of other countries' achievements in colleges and universities and guided by the idea of " combining the in-class and after-class, combining the science and humanities" .Aim at training the automobile majors' practical and innovative ability couple with integrating the three practice step--the campus practice(experiment, curriculum design ), the off-campus practice(production practice) and the practice in school-enterprise IAR. To build a multifaceted and multi-angle student practicing and learning platform which composed by the off-campus production practice base, the intramural laboratory and the school-enterprise research center, and which aim at improving students' practical and innovative ability as well as improving the quality of applied talents, to make a contribution to the local economy and construction. The specific contents are as follows:

\subsection{Build a automobile majors' curriculum system of innovation and practice}

By the means of literature retrieval, field survey and investigation, etc. to develop the macroscopic theory research and sets up a new professional course cata$\log$. According to the rapid development of automobile industry, to set up a series of new technology course in the training program and set up a series of innovative curriculum in the second-class. Moreover, to combine the automobile majors' general innovative training plan and set up sub-projects' schedule as well as assessment manage methods, and to design innovation education management system.

\subsection{Build a automobile majors' innovative practice training plan and incorporate it, in credit system, into the innovation practice ability training scheme}

Build a "Student Innovation Training Plan "which integrated by second-class activities including extracurricular activities of science and technology, academic competition, social practice and vocational skill training. The plan should include four aspects: scientific research innovation training program, technology race plan, humanistic literacy improving plan and vocational skills training programs, each aspect has some sub-projects which including some specific activities. Then incorporate the 4 aspects above into innovative practice training plan in the form of credit, as students graduate credit.

\subsection{Build the Three-in-one practice platform}

Consolidate and standardize the production practice base out campus, then opening up new students production practice base, perfect lab construction and running management in campus, increase the openness of the laboratory ,promoting teacher's studio cooperation with research enterprises ,the construction and regulation of $\mathrm{R} \& \mathrm{D}$ centers of college and enterprises.

(1)Clearly multidimensional practice learning platform is under the instruction of teacher, from the creation of problem situations, effectively stimulate students to actively explore innovative knowledge and ability to acquire knowledge, learning activities which apply knowledge to solve problems ,make the idea come true that students as center, combining curricular and ex-curricular, teaching and researching.

(2)Norms and strengthen the construction of the teacher's studio. Build the teacher's studio according to the direction of research and specialty of teacher. Made clear management and assessment objectives on studio. Take it into assessment that teacher make students into studios promote teacher studio and business volume and create R \& D center, so that both teaching and researching can improve. 
(3)Optimize the student internship link. Make through all the Basic Course and related experiment,course design,production internship,graduation internship and graduation project. Classified practical teaching into basic engineering training, comprehensive basic engineering training and comprehensive engineering training. Basic engineering training include basic experiment of basic professional courses and basic experiment of professional direction courses, such as Metalworking Practice, Electronic Technology Practice, Mechanical principles, Automotive Electronics Technology, Mechanical Control Engineering, Micro controller Theory and its related experiment of basic courses. Comprehensive basic engineering training include professional basic courses and comprehensive experiment of professional direction courses, such as course design of automotive theory, course design of automobile design, comprehensive experiments of automobile construction. Comprehensive engineering training majorly consists of production internship, graduation design of automotive specialties.

Considered the relations of different level's practical teaching, Conduct basic courses and specialized courses pro- fessional courses experiment, curriculum design, production practice, graduation design, detailed engineering technical practice teaching optimal design, presents specific plan. Emphasize foster students practical ability and application ability in this plan.

\subsection{The optimization of the innovative practice ability training teaching quality assurance system}

The optimization of innovative practice ability teaching quality assurance system including optimize the methods of innovative practice teaching and improve the assessment methods of innovative practice teaching. On the basis of optimization and system planning of innovative practice teaching system, should research on optimizing assessment methods of the innovative practice teaching. Because teaching methods directly affect students' learning motivation and teaching results. In the traditional practice teaching, the students' active participation is not enough. They are always just do some mechanical imitation during the practice which can't training their engineering practice ability and innovative design ability.

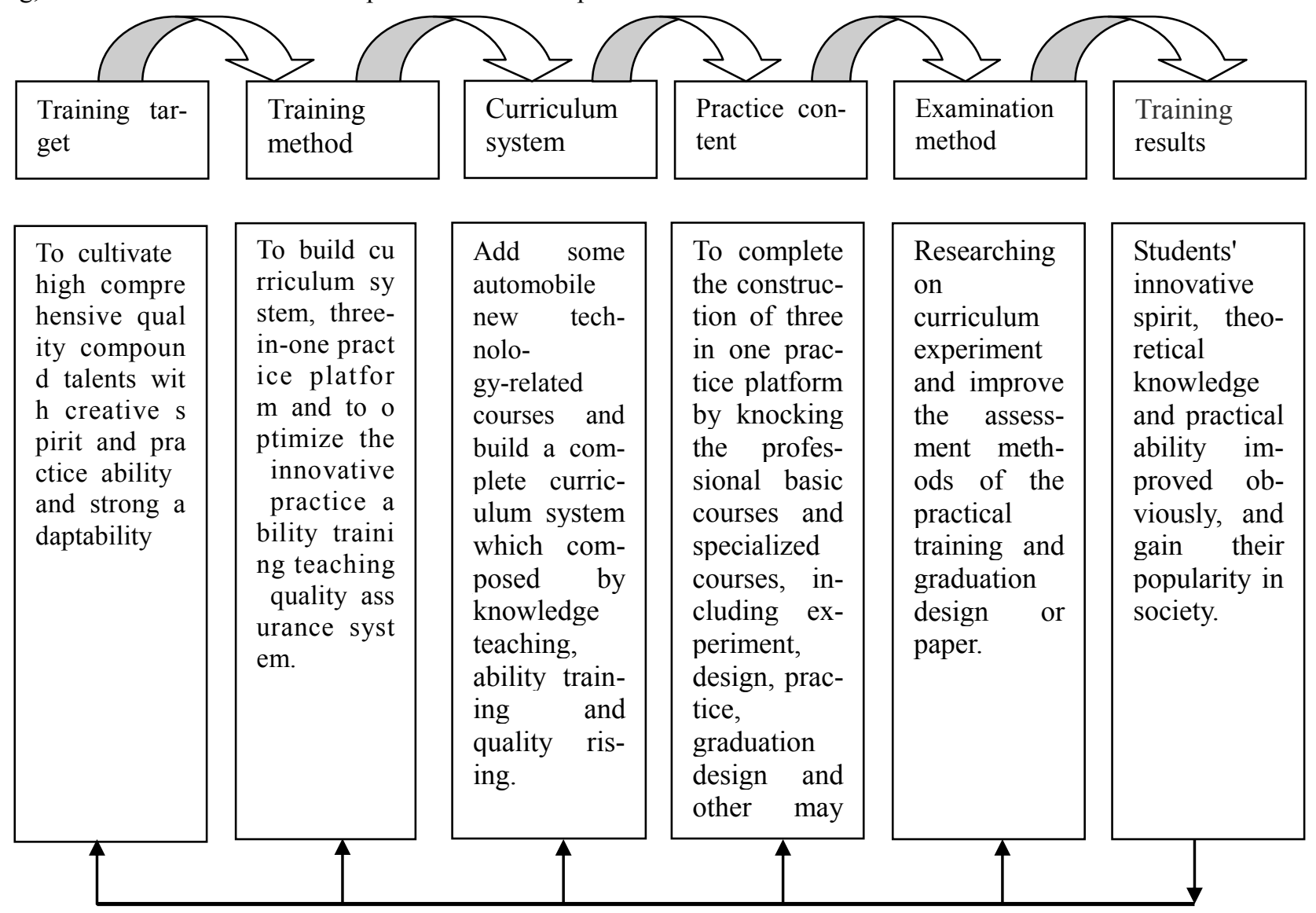

Feed

back

Fig. 1 Innovation practice ability training plan 
To optimize the teaching quality keeping system, it can be done by improving management of teaching process, enhance the instruction of student's practical experiment. Meanwhile, be an exemplary role as an experimental teacher; strengthen student's participation in practical experiment, by taking groups practice, independent experiment and other forms of experiments to improve student's practical ability. At meantime, based on the necessary validation experiments ,plus comprehensive design experiment and researching innovation experiment, then combined with media teaching, physical education, simulation experiment all kinds teaching methods to open the horizon of student's practical experiment, developing student's innovation ability and ability of solving existing problems. Besides, scientific evaluation method is an important part of improving effect of innovation practical teaching, according to different types of practical teaching, researching the improvement of course's experiment and e assessment of course's design, evaluation of practical experiment, graduation design. The assessment should focus on students' initiative, practical ability, ability of experiment design and innovation ability in the process of innovation practical experiment. CONCLUSION

Due to our traditional concepts of education and the rapid development of automobile technology, in terms of teaching content, we put more concentration on theory instead of practice, our curriculum is old, our settings are not reasonable, so there are a lot of problems we should improve and perfect in innovative practice teaching system design and optimization, etc. in automotive specialties to adapt to the new situation of the country's development. So this paper focused on the current situation and problems of teaching, combined with the essential feature of automotive specialties teaching, take improve students' innovative ability and practical ability as a target, major innovation practice ability of automotive teaching and research work.

Take fostering students' creative ability and practical ability as a fundamental target and build college students' innovation practice education system, take college students' innovation practice plan as a core to set up innovation practice credits, put it into professional training program, thus achieving first class and second class activities organic interactive, set up environment and opportunities for students' personalities and abilities development, build a platform for college students' innovation practice activities.

This paper put forward a special idea that we could design and optimize the practical teaching system by phases and hierarchical, at meantime, scientifically regular the system, avoid the practical teaching out of line and unnecessary repeat. Emphasize students' practical ability and overall innovation capability, it mean a lot in fostering senior applied talents in automotive field which our current internal economic construction.

This paper's result will greatly optimize the existing training mode, strengthen comprehensive reform in professional, curriculum and teaching methods, teaching students by advanced scientific knowledge, penetrating the Quality Education into professional education, enable students to participate in scientific research and social production practices earlier, improve students' scientific quality, innovative spirit and practical ability, enhance competitiveness and improve social employment rate.
Consolidate and standardize the production practice base out campus, then opening up new students production practice base, perfect lab construction and running management in campus, increase the openness of the laboratory ,promoting teacher's studio cooperation with research enterprises ,the construction and regulation of $\mathrm{R} \& \mathrm{D}$ centers of college and enterprises.

\section{ACKNOWLEDGEMENTS}

The study is sponsored by "Hunan Provincial Natural Science Foundation of China(Grant No. 2015JJ2001)"and "The Research Foundation of Education Bureau of Hunan Province, China(Grant No.13C1015)" and "The Foundation for Changsha University of Science and Technology teaching reform project (Grant No. JG1342)"

\section{REFERENCES}

[1] Lv Hongming. Take "the Excellence Project"as an Opportunity to Explore the Talent Training of Automotive Engineering for Local Colleges[J].Value Engineering, 2011,30(14): 219-220.

[2] WEN Xiaoxia,DU Zixue,SUN Qing. Thinking of New Model for Training Automotive Professional in China[J]. Journal of ChongQing JiaoTong University(Social Sciences Edition), 2008,8(5):108-109.

[3] Zhou Jialun. Innovative Talent Training and College Students' Comprehensive Quality Education[J].China Higher Education, 2006,42(5):25-27.

[4] Cao Yin'gu.The construction of college students' innovation ability index system research[D].Wuhan University of Technology,2008.

[5] Zhang Wusheng. Research on Creative Thinking and Personality Teaching Mode[J].Journal of Tianjin Academy of Educational Science, 2000,12(5): 33-37.

[6] Su Li,Lan Hai. Discuss the research-based teaching model-Based on the perspective of cultivating senior applied talents[J],Heilongjiang Researches on Higher Education, 2008, 12: 175-176.

[7] Busenitz L, W West and Shepherd D. Entrepreneurship Research in Emergence: Past Trends and Future Directions[J]. Journal of Management, 2003, 29(3):95-305

[8] Wu Minghui,Yan Hui,Chen Guanlin,etc.Research on The Multi-dimensional Practice Teaching System[J].Research in Higher Education of Engineering,2007,25(S1): 71-73.

[9] Wu Xianming,Liu Houcai.The Construction and Research of the Strengthen the Practice Teaching,Training Innovation Ability and Practice Textbook[J].Theory and Practice of Contemporary Education, 2011, 3(7): 82-84.

[10] Lin Jian,Fu Hanguang,Wu Zhongwei,etc.Teaching and Experience about the College Practice Innovation Courses[J].Theory and Practice of Contemporary Education, 2010, 2(6): 72-74. 